\title{
Discussion
}

Apolinario, E. (Argentine). Our experience with the procedure of motor point block is not very large so far. We used it only in a few cases with incomplete lesions where muscle power and sensation must be preserved. The procedure we use is more or less the same as described by Dr. Glass, but we use weaker concentrations and we will keep his higher concentrations in mind for the future because our results are not very long lasting. We usually perform an electromyography of the muscles to be blocked before any procedure was applied. Then a test with procaine solution is made at a concentration of 0.5 to I per cent. and thenthe electromyographic record is repeated. If the results are satisfactory we proceed with the definite blocking with 2 per cent. aqueous phenol solution only but in future, we will use stronger concentrations.

\section{PATHOLOGICAL FINDINGS FOLLOWING THE INTRATHECAL INJECTION OF ETHYL ALCOHOL IN MAN}

\author{
By J. Trevor Hughes, M.D. \\ From the Oxford Hospitals and the National Spinal Injuries Centre, Stoke Mandeville \\ Hospital, Aylesbury
}

THE therapeutic injection of alcohol into the subarachnoid space in man for the treatment of pain was first described by Dogliotti (I93I), and the similar use of phenol dates from the report of Maher (I955). These therapeutic injections were devised for the relief of chronic pain, but subsequently both substances have been used to relieve the painful spasms associated with paraplegia. Whilst the chemical toxic effect of the two agents is very similar, the method of administration differs. Alcohol being hypobaric with respect to cerebrospinal fluid rises in the subarachnoid space and, to affect the caudal part of the spinal cord and its roots, the alcohol is given slowly (to avoid rapid mixing with C.S.F.) with the patient in the prone head-down position (Tank, et al., I963). Phenol is given mixed with a radio -opaque solution such as myodil and the resultant heavy mixture descends in the spinal cord and affects the dependent part of the nervous system.

In the treatment of chronic intractable pain phenol is often preferred to alcohol and it is probable that with the careful positioning of the patient a more selective effect can be obtained with phenol. However, in the special problem of intractable spasticity in paraplegia and tetraplegia it has been found by Guttmann (1946, I953), Sheldon and Bors (1948) and others that alcohol gives most satisfactory clinical results. It is not my intention to discuss the clinical use of these agents, but to give my own observations on the resulting pathological changes. There have been several detailed reports on the pathological findings after the subarachnoid injection of phenol (Berry \& Olszewski, I963; Smith, 1964) but fewer and less detailed observations on the findings in alcohol injection. Consequently my own findings may be of value since they are based on cases from Stoke Mandeville Hospital where intrathecal alcohol has been extensively used since I 946.

The principal clinical features of the six cases which have been studied in 
detail are given in the Table. In the account that follows the emphasis is on the microscopical findings in the spinal cord and its nerve roots. In all the cases transverse sections of the spinal cord were cut at a large number of segmental

TABLE

\begin{tabular}{|c|c|c|c|c|c|}
\hline Case No. & $\begin{array}{l}\text { Sex and } \\
\text { Age }\end{array}$ & Diagnosis & $\begin{array}{l}\text { Alcohol } \\
\text { Injection }\end{array}$ & $\begin{array}{l}\text { Duration of } \\
\text { Paraplegic } \\
\text { Life }\end{array}$ & $\begin{array}{c}\text { Survival after } \\
\text { Alcohol } \\
\text { Injection }\end{array}$ \\
\hline I. D. C. & M. 55 & $\begin{array}{l}\text { Necrotic } \\
\text { Mvelopathy }\end{array}$ & $8 \mathrm{ml}$ & 8 months & 4 months \\
\hline 2. F. H. & M. 70 & Cervical spine injury & $4 \mathrm{ml}$. & 5 years & 3 years \\
\hline 3. W. L. & M. 68 & Cervical spine injury & $4 \mathrm{ml}$. & 8 years & 6 years \\
\hline 4. W.S. & M. 69 & $\begin{array}{l}\text { Compression } \\
\text { fracture of Tio }\end{array}$ & $4 \mathrm{ml}$ & I I years & 8 years \\
\hline 5. W. W. & M. 50 & $\begin{array}{l}\text { Fracture disclocation } \\
\text { at } T_{9-10}\end{array}$ & $8 \mathrm{ml}$. & I 4 years & 8 years \\
\hline 6. R. E. & M. 70 & Cervical spine injury & $\begin{array}{r}0.4 \mathrm{ml} \text {. } \\
2 \mathrm{ml} .\end{array}$ & 2 I years & 20 years \\
\hline
\end{tabular}

levels and many sections were prepared of the cauda equina. In addition to simple cell stains (Nissl, Haematoxylin and Eosin) the sections were stained for connective tissue (Haematoxylin and Van Gieson), myelin (Weil), and axons (Holmes).

\section{MICROSCOPICAL FINDINGS IN THE SPINAL CORD}

The histological observations permitted in these cases may be considered under the headings of Meninges, Spinal Vessels, Spinal Cord, and Spinal Nerve Roots.

Meninges. The dura mater in all cases was normal and there were no adhesions between the dura mater and the arachnoid mater that could be attributed to the alcohol injection. The arachnoid mater and the pia mater were always thickened by fibrosis (fig. 5). In many instances the subarachnoid space was obliterated by fibrosis, and in the majority of the sections these two meningeal layers were united at several points. The stage of fibrosis was that of acellular collagenous connective tissue thickening except in Case I (4 months after alcohol injection) when some cellular connective tissue in the last stages of organisation remained. There was no significant difference between Case 2 (3 years after alcohol injection) and Case 6 (20 years after alochol).

Spinal Vessels. With one exception no abnormality of the major spinal arteries was seen. The exception was that in Case 5 at T8 segmental level there was evidence of old thrombosis of the anterior spinal artery and the spinal cord in this region showed a glial and connective-tissue scar suggestive of an old region of infarction. The site of this old anterior spinal artery occlusion, which was only 
found at T8 segmental level, was above the region of maximum damage to the spinal cord incurred by the injury sustained by this man. It was considered that the thrombosis was a consequence of the spinal injury and had no connection with the subsequent alcohol injection.

The meningeal vessels were chiefly abnormal in being surrounded by condensations of acellular connective tissue. The intramedullary vessels were either normal or had changes that could not be ascribed to the effects of alcohol.

Spinal Cord. The spinal cords (figs. I, 2, 3) showed evidence of direct damage and secondary changes due to lesions of the spinal nerve roots. The direct damage was seen as a peripheral rim of myelin and nerve fibre loss which had been transformed into a zone of astrocytic gliosis merging into the connective tissue fibrosis of the pia mater (fig. 6). This change extended evenly around the spinal cord and was most marked in the course medullaris. The depth of this peripheral rim of gliosis varied but it was never more than $0.5 \mathrm{~mm}$.

The indirect changes seen in the spinal cord were secondary to lesions of the spinal nerve roots and were of two types, Wallerian degeneration in the posterior white columns (figs. I, 2, 3) and central chromatolysis in the anterior grey horns (fig. I). The Wallerian degeneration was seen in the gracile fasciculi of every case

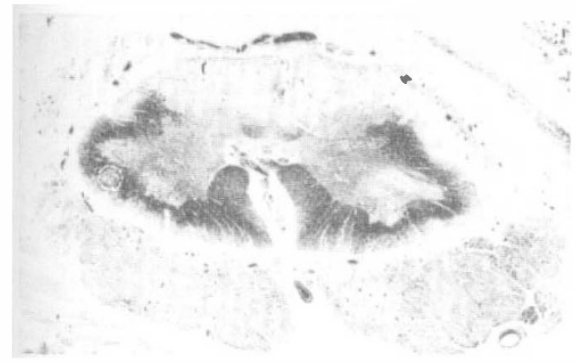

FIG. I

Figure I-Case 2. Transverse section, stained for myelin, of spinal cord at $\mathrm{S}_{2}$ segmental level. Note the degeneration of the nerve roots (posterior more than anterior) and Wallerian degeneration of the posterior columns. There is a peripheral rim of spinal cord damage. (Weil $\times 7$ ). Figure 2-Case 3. Transverse section, stained for myelin, of spinal cord at L3 segmental level. Note the degeneration in the nerve roots and the posterior columns. (Weil $\times$ IO.)

and was a severe depletion of myelin and nerve fibre in all cases except Case 6. The stage of the degeneration in Case I was that of a cellular microglial proliferation, whilst in Case 2 there was commencing astrocytic gliosis. In Cases 3, 4, 5 and 6 the gracile fasciculi were replaced by an inactive astroglial scar. Central chromatolysis was seen in the motoneurones of the anterior horns in Case I (survival 4 months) and Case 2 (survival 3 years) but not in Cases 3, 4, 5 and 6 (survival $6,8,8$ and 20 years). 
Spinal Nerve Roots. In all cases except Case 6 a severe destructive lesion of the caudal nerve roots was present. Case 6, in which smaller amounts of alcohol $\left(0^{\circ} 4 \mathrm{ml}\right.$. and $2 \mathrm{ml}$.) had been used, showed lesser changes. The cauda

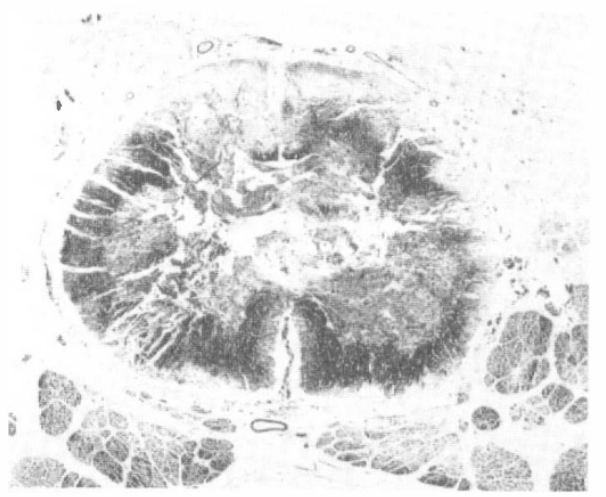

FIG. 3

Case 5. Transverse section, stained for myelin, of spinal cord at $S_{3}$ segmental level. Note the marked degeneration of the posterior nerve cells as compared with the anterior nerve roots. Posterior column Wallerian degeneration can be seen. (Weil $\times 9$.) equina was the most severely affected region with only traces of damage to the lower thoracic and upper lumbar roots. In all cases the degeneration was more extensive in the posterior than the anterior spinal nerve roots (figs. 3,4 ). In the majority of the posterior roots the hole root was degenerated with fibrosis replacing the degenerated myelin and axons. Where roots were only partially affected the damage was most evident in the peripheral part of the nerve root.

Aberrant Nerve Fibres. In all cases except Case I there were small bundles of irregular myelinated nerve fibres in the subarachnoid space. These were always most prominent in the anterior part of the cord and were particularly well seen in the anterior median sulcus (fig. 8). Occasionally the abnormal fibres were seen in a perivascular space in the grey commissure of the spinal cord. These abnormal fibres were thought to arise from the anterior horn cells via the anterior spinal nerve roots. They could not have arisen from the posterior nerve roots which were almost completely devoid of nerve fibres.

\section{DISCUSSION}

The histological findings in the cases indicated that the nature of the damage which follows subarachnoid injection of alcohol is a toxic radiculitis and myelitis with leptomeningeal fibrosis causing adhesions to obliterate parts of the subarachnoid space. The toxic effects observed were minimal in Case 6 , in which only $0^{\circ} 4$ $\mathrm{ml}$. and $2 \mathrm{ml}$. of alcohol had been used, but no significant difference was seen in the other cases in which either $4 \mathrm{ml}$. or $8 \mathrm{ml}$. of alcohol had been used. These findings suggest that to exert the maximum effect, as judged by histology at necropsy it would be pointless to exceed the doses $(4 \mathrm{ml}$. and $8 \mathrm{ml}$.) used in Cases I- 5 .

The most important sequel to the alcohol injections was a toxic radiculitis which involved chiefly the roots of the cauda equina. There was a contrast between the degeneration of the posterior and of the anterior nerve roots. The posterior roots, in Cases I-5, were almost completely depleted of myelin and nerve fibres and were often totally replaced by organised fibrous tissue. In nerve roots where the damage was incomplete it was clear that the peripheral part of the nerve root was the part most severely affected. These findings indicate a direct toxic effect on the nerve fibres coming into contact with the injected alcohol. It is 


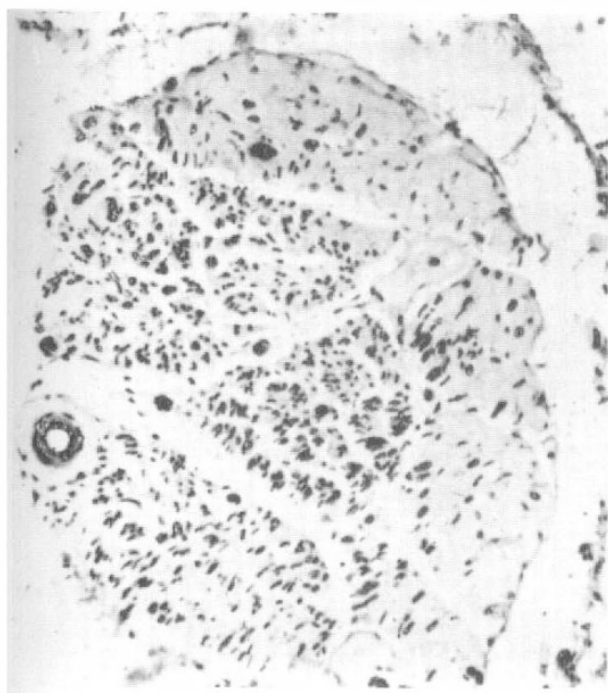

FIG. 4A

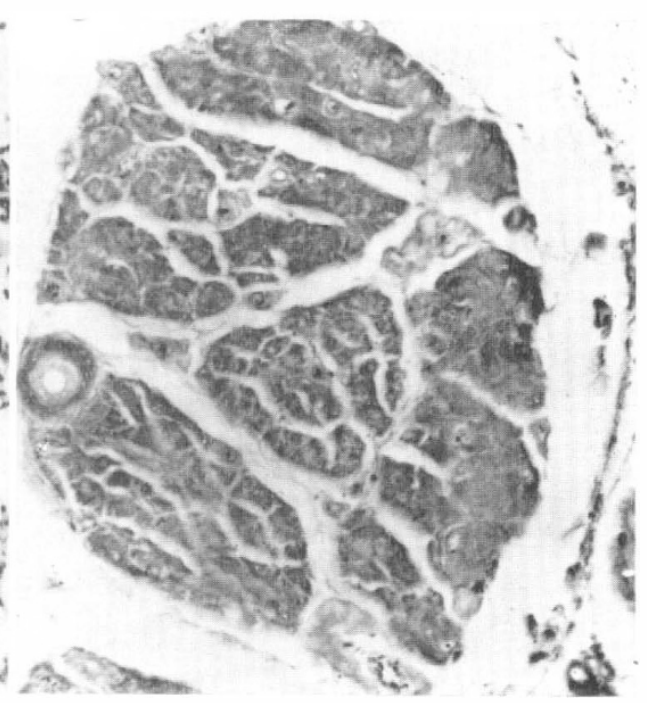

FIG. 4B

Figure $4 \mathrm{~A}-$ Posterior root showing severe depletion of myelinated fibres. The peripheral part of the nerve root is the worst affected. (Weil $\times$ I23.) Figure $4 \mathrm{~B}-$ Same root as in Figure 4A stained with silver. Only a few scattered axons remain. (Holmes $\times$ I23.)

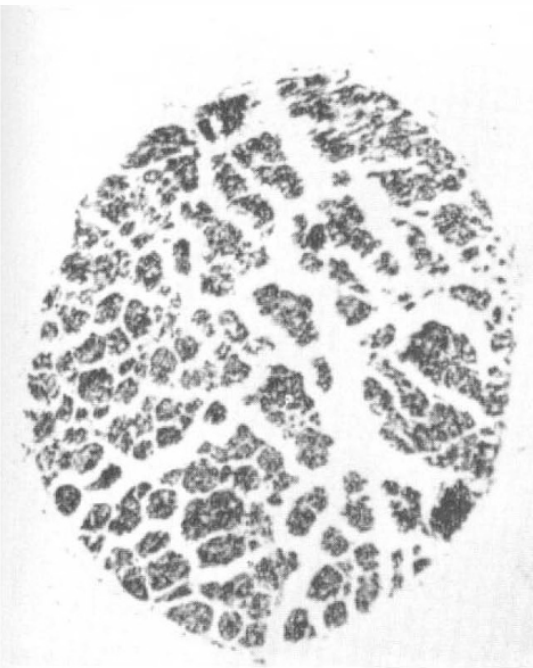

FIG. 4C

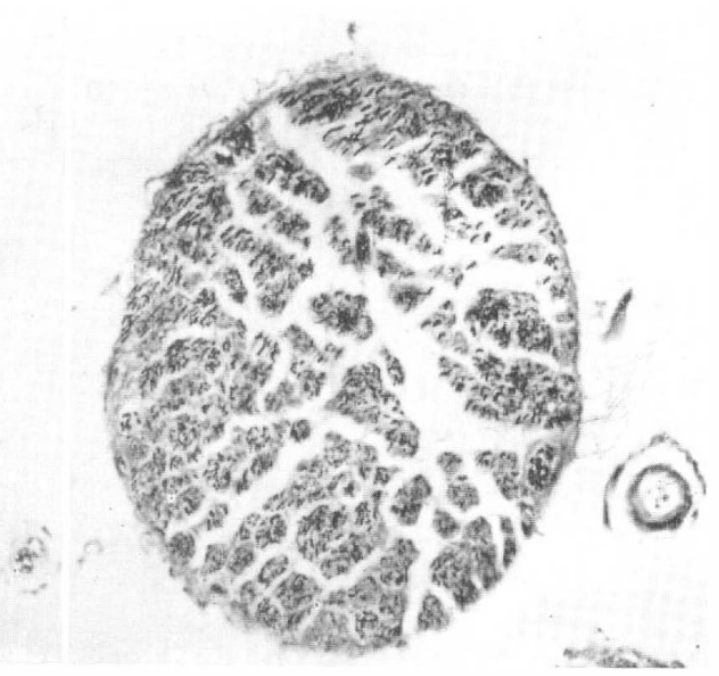

FIG. 4D

Figure $4 \mathrm{C}-$ Anterior root stained for myelin and showing only slight depletion of myelinated fibres. (Weil $\times$ I23.) Figure $4 \mathrm{D}-$ Same root as in Figure $4 \mathrm{C}$ stained with silver. Slight depletion of axons can be seen, the damage being to the periphery of the nerve root. Note the contrast between the fibres here and those in Figure 4B. (Holmes $\times$ 123.)

Case 5.-These are photomicrographs from the same case as illustrated in Figure 3. The sections are from the same segmental level $\left(\mathrm{S}_{3}\right)$ and are stained for myelin (on left) and axons (on right). 


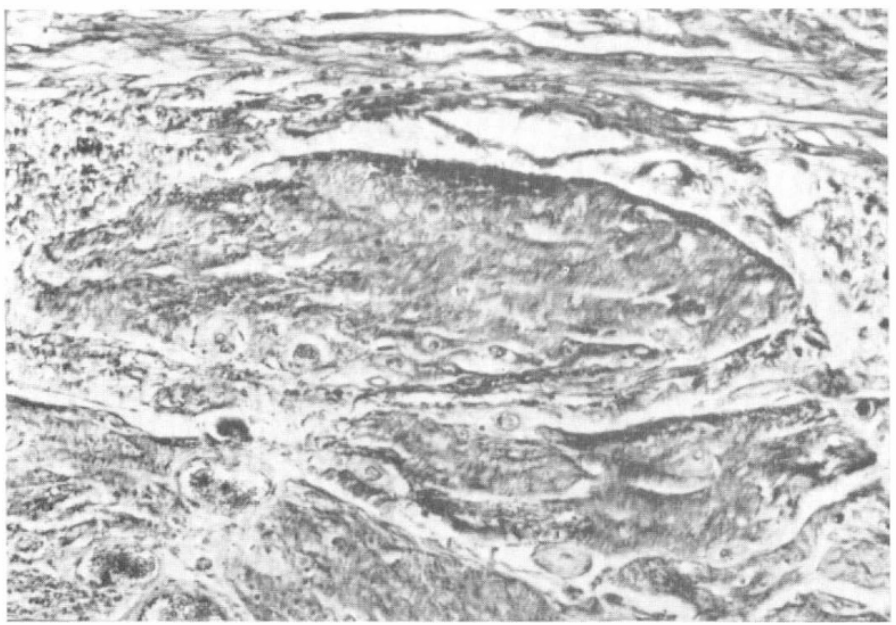

FIG. 5

Case 2. Photomicrograph of transverse section of spinal cord at $\mathrm{S}_{2}$ segmental level. The picture shows atrophied posterior nerve roots involved in dense collagenous scar tissue. The layers at the top of the picture are thickened arachnoid. (Haematoxylin and Van Gieson, $\times$ I70.)

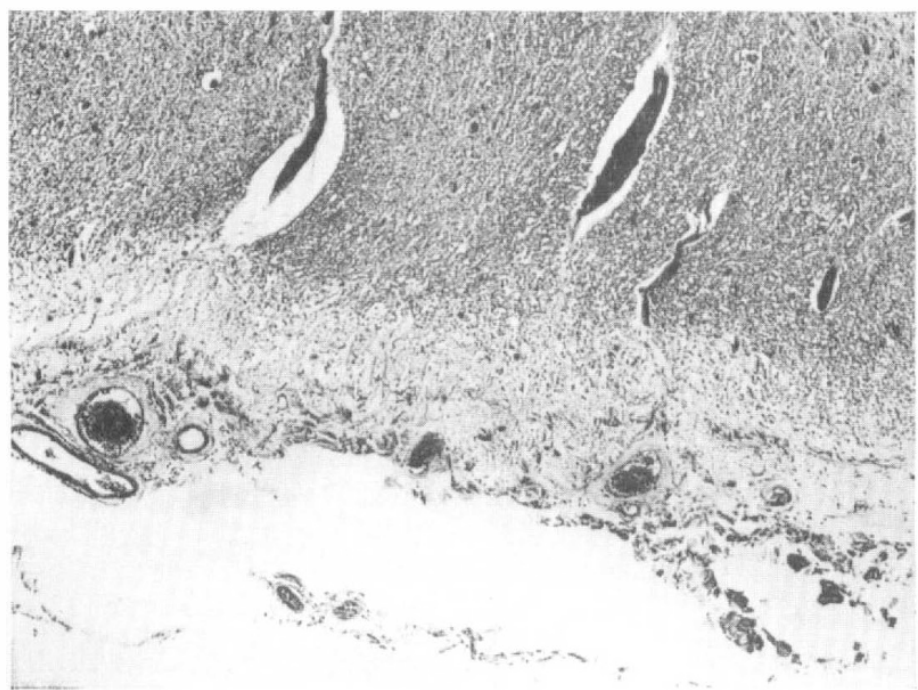

FIG. 6

Case I. Photomicrograph of transverse section of spinal cord at $\mathrm{S}_{2}$ segmental level. The picture shows the peripheral rim of degeneration with gliosis that surrounded the spinal cord.

(Haematoxylin and Van Gieson, $\times 58$.) 
possible that the preferential involvement to the posterior nerve roots was due to the positioning of the patient during the alcohol injections but there is an alternative explanation to these findings. It may be that regrowth of damaged anterior root fibres is possible from the intact anterior horn cell bodies. Evidence that this regrowth was taking place was seen in the aberrant nerve fibres seen in the subarachnoid space and in particular the anterior median sulcus. The significance of this phenomenon has been discussed elsewhere (Hughes \& Brownell, I963).

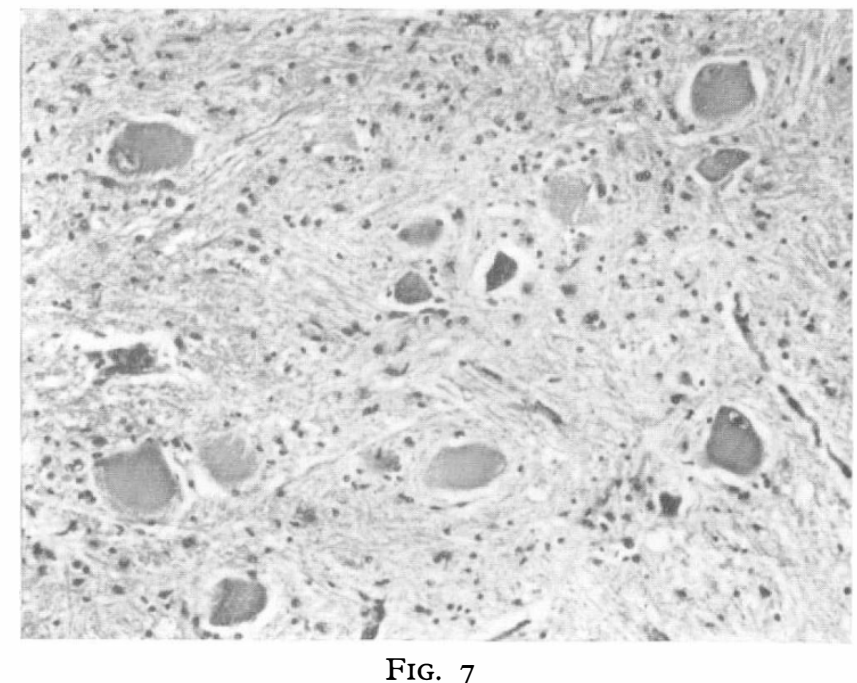

Case I. Photomicrograph of anterior horn cells at 52. Many of the neurone cell bodies show central chromatolysis. (Haematoxylin and Eosin, $\times$ I32.)

These cases also provide evidence for the time sequence of the changes of central chromatolysis (Hughes, I966). Central chromatolysis, the effect on the parent neuronal body following axon section, was seen in Case I (survival 4 months) and Case 2 (survival 3 years) but not in Cases 3, 4, 5 and 6 (survival 6, 8, 8 and ro years). These findings suggest that central chromatolysis persists as a recognisable phenomenon for 3 years after axon damage after which the appearances in the motoneurone revert to normal. This cycle of histological change is much longer than that deduced experimentally by Brodal (Hughes, I966) in adult mammals.

\section{SUMMARY}

The pathological findings at necropsy in six cases of paraplegia treated with subarachnoid ethyl alcohol injection are described.

The most important sequel to the alcohol injections was a toxic radiculitis involving the cauda equina and resulting in more severe degeneration of the posterior than the anterior spinal nerve roots.

A toxic myelitis involving a small peripheral rim of the caudal part of the spinal cord and leptomeningeal fibrosis causing partial obliteration of the subarachnoid space were also found. 
The presence of regenerating myelinated nerve fibres of peripheral nerve type in the subarachnoid space is described. discussed.

The time sequence of the histological changes of central chromatolysis is

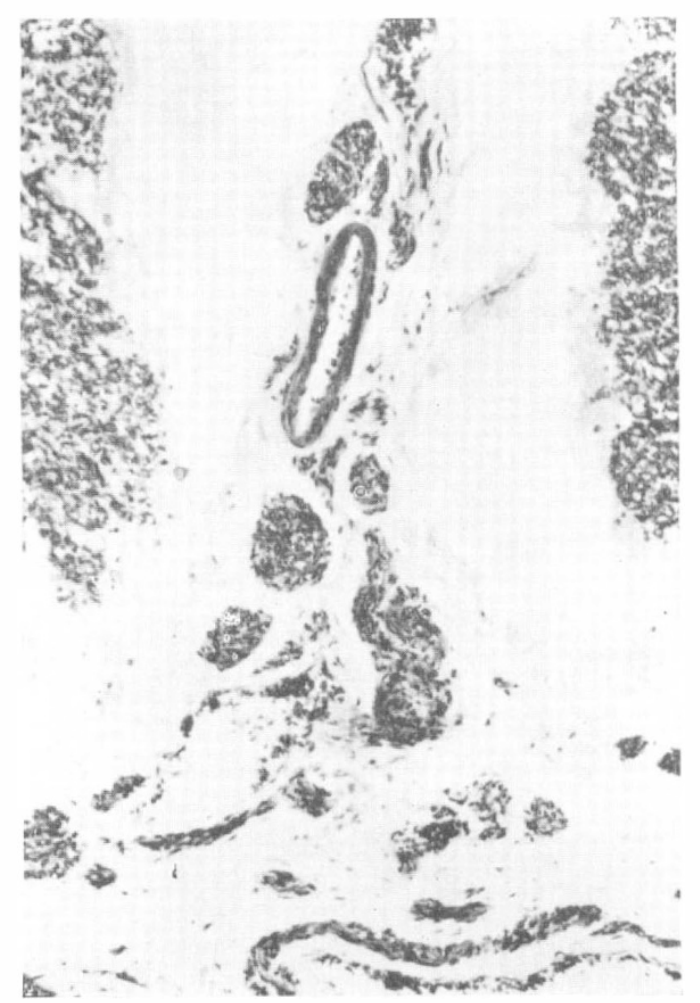

FIG. 8

Case 5. Photomicrograph of a transverse section of the spinal cord at $S_{3}$ segmental level. The picture shows the anterior median sulcus in which there are bundles of aberrant myelinated fibres having the characteristics of peripheral nerve. (Weil, $\times$ I23.)

\section{ACKNOWLEDGEMENT}

I should like to thank Dr. H. J. Harris of the Pathology Department, Stoke Mandeville Hospital, for making available to me cords of the necropsies which were all performed in his department. All the patients during life were under the care of Sir Ludwig Guttmann, to whom I am indebted for the use of his clinical records.

\section{REFERENCES}

Berry, K. \& Olszewski, J. (1963). Neurology (Minneap), 13, I52-I54. Dogliotti, A. M. (193I). Presse med. 39, I249-I252. 
Guttmann, L. (1946). Proc. Roy. Soc. Med. 40, 219.

Guttmann, L. (I953). Brit. History of World War II, Vol. Surgery, 457. London: H. M. Stationery Office.

Hughes, J. T. (1966). Pathology of the Spinal Cord, p. 3. London: Lloyd-Luke.

Hughes, J. T. \& Brownell, B. (1963). F. Neurol. Neurosurg. Psychiat. 26, 528-534.

MAHER, R. M. (1955). Lancet, I, I 8-20.

SHELDON, C. H. \& Bors, E. (I948). F. Neurosurg. 5, 385.

Smith, M. C. (1964). Brit. F. Anaesth. 36, 387-406.

TANK, T. M., DOHN, D. F. \& GardNER, W. J. (I963). Cleveland Clin. Quart. 30, I I I-I I 7.

\title{
AXON REGENERATION AFTER SPINAL CORD INJURY
}

\author{
By Lionel Wolman, M.A., M.D., PhD., M.R.C.P., D.P.M. \\ Department of Neuropathology, Royal Infirmary, Sheffield, 6
}

THE long-held belief that regeneration in the central nervous system does not occur has been questioned on numerous occasions both as a result of work on experimental animals and by observations on human pathological material. Thus regeneration within the central nervous system of amphibia has been demonstrated by Hooker (I915, I9I7, I925), Lorente de No (I921), McCreight (I924), Piatt (1955) and Stephens (1959). In mammals, after experimental transection of the cord, regeneration was shown by Denton (I873), Eichhorst and Naunyn (I874), Stroebe (I894), Nageotte (I899), Cajal (1928) and Murray et al. (1965). This regenerative capacity was much greater in embryonic or newborn animals (Gerard \& Grinker, I93I; Nicholas \& Rudnick, I933). Evidence of intraspinal sprouting of dorsal root axons with the development of new collaterals and preterminals following partial denervation of the spinal cord was shown in the cat by Liu and Chambers (1958). Regenerating fibres from both the cord tracts and spinal roots were demonstrated in the rat after cord transection by Sugar and Gerard (1940), but these observations could not be confirmed by Feigin et al. (I95I). Invasion of the spinal cord by axons from ventral nerve roots was demonstrated by Wohlfart (I96I).

In human material, the regenerative capacity of the central part of the posterior nerve roots has been frequently noted in spinal cord injury. The regenerated fibres entering the cord are covered with Schwann cells and are well myelinated. Thus Minor (1904) recognised bundles of myelinated fibres in the scar of the cord of patients with old traumatic lesions. Marinesco and Minea (I906) examined two cases of spinal cord compression due to dislocation of the first lumbar vertebra and found regenerated fibres accompanying blood vessels in the anterior median fissure, leptomeninges round the cord, in the posterior roots, in the scar and nearby grey matter. Henneberg (1907) found regenerating fibres in the leptomeninges covering the dorsal columns and extending into the cord in total transverse lesions of the cord. He believed they originated from posterior nerve roots. A similar origin was attributed by Klaue (I949) to the fibres seen in the scar of a grenade wound of the cord. 